Jurnal Teknologi, 44(A) Jun 2006: 97-114

(C) Universiti Teknologi Malaysia

\title{
VISION BASED AUTOMATIC STEERING CONTROL USING A PID CONTROLLER
}

\author{
AHMAD SAIFIZUL ABDULLAH ${ }^{1^{*}}$, LOO KIM HAI ${ }^{2}$, \\ NOOR AZUAN ABU OSMAN ${ }^{3} \&$ MOHD ZAMRI ZAINON ${ }^{4}$
}

\begin{abstract}
Automatic steering control is a vital component of highway automation, currently investigated worldwide in several Intelligent Transportation Systems (ITS) programs. The promise of Intelligent Transportation System lies in the possibility of increasing the capacity of existing highways by safer and more efficient use of available space. This system will include completely "hands-off" driving in which vehicles are fully automatically controlled once they enter the system. In order to achieve the above objective, the Proportional-Integral-Derivative (PID) controller and vision based concept to an automatic steering control system is used to cause the vehicle to track the reference under various conditions. Simulation results show that the proposed control system achieved its objective even though it is less robust in maintaining its performance under various conditions.
\end{abstract}

Keywords: Automatic steering control, vehicle dynamics, vision system, PID controller

\begin{abstract}
Abstrak. Kawalan stereng automatik adalah satu komponen penting dalam pengautomatan lebuhraya, yang kini diselidik di seluruh dunia di bawah beberapa program Intelligent Transportation System (ITS). ITS berpotensi meningkatkan kapasiti lebuhraya yang sedia ada dengan penggunaan yang lebih selamat dan lebih efisien terhadap ruang yang sedia ada. Sistem ini akan terdiri daripada konsep pemanduan "hands-off" secara menyeluruh yang mana kenderaan akan dikawal secara automatik apabila ia memasuki sistem itu. Untuk mencapai objektif di atas, pengawal PID dan konsep dasar penglihatan ke atas sistem kawalan stereng automatik digunakan untuk membolehkan kenderaan menjejak rujukan di dalam pelbagai keadaan. Keputusan simulasi menunjukkan bahawa sistem kawalan yang dicadangkan mencapai objektifnya meskipun ia kurang lasak untuk mengekalkan prestasinya di dalam pelbagai keadaan.
\end{abstract}

Kata kunci: Kawalan stereng automatik, dinamik kenderaan, sistem penglihatan, kawalan PID

\subsection{INTRODUCTION}

Automatic steering control is a vital component of highway automation, investigated worldwide in several programs. Overviews of highway automation were given by Bender [1] and Shladover [2]. Automatic steering control of vehicle has been studied since late 1950's [3]. Automatic steering control problem requires addressing two parts: sensing and control. Automatic steering control approaches can be grouped

$\overline{1,2,3 \& 4}$ Department of Mechanical Engineering, Faculty of Engineering, Universiti Malaya, 50603, Kuala Lumpur, Malaysia

* Corresponding author: Tel: 03-7967 4495, Fax:03-79675317, Email: saifizul@um.edu.my 
into look-ahead and look-down systems. Look-ahead systems replicate human driving behavior by measuring the lateral error ahead of the vehicle. A number of research groups have successfully conducted highway speed experiments with look-ahead systems like machine vision [4] and radar reflective stripes [5]. Another approach is the look-down system which measures the lateral displacement at a location within or in the close vicinity of vehicle boundaries, typically straight down the front bumper. However, despite an impressive amount of literature on control design based on look-down systems [6-9], no highway speed experiments has been reported. This means that look down reference system is limited to low speed [10]. From the point of view of control, several methods have been applied to achieve the purpose of automatic steering control to cause vehicle to track along a reference path with small error automatically [11-17]. A simple Proportional-Integral-Derivative (PID) controller based on the output from a look-down system has been suggested since 1990 [11]. An experiment study on this PID controller was done in 1991 [18]. The researchers concluded that the implementation of a PID with feedforward control action based on look-down approach showed good performance in terms of tracking under nominal conditions. However, the limitations of such a controller were observed as nominal parameters deviated from their nominal values. In 1996, Kosecka [19] demonstrated that with a proportional controller only; by using look-ahead system, the vehicle can reliably track changes in curvature up to $0.004 \mathrm{~m}^{-1}$ with velocity up to $28 \mathrm{~ms}^{-1}$. In an attempt to extend the research in this area, this paper proposes a more practical vision dynamics and introduces a PID controller with look-ahead system to vision based automatic steering control systems.

\subsection{MATHEMATICAL MODELING}

Vehicle model has been studied since late 1950's. Vehicle models with 6 degree of freedoms were developed by Lugner [20], and Peng and Tomizuka [21] to represent the vehicle as realistically as possible. This model is complex and not suitable for controller design. According to Peng and Tomizuka [11], a linear and simplified model which retains only the lateral and yaw motion dynamics has been proven sufficient for studying car steering under nominal conditions, i.e. non-emergency situation.

\subsection{Vehicle Model}

The simplified two degrees of freedom linear vehicle model is obtained from the complex vehicle model by considering the vehicle is not accelerating along the longitudinal axis and assuming that there are no external forces acting on the vehicle. The linear vehicle model can be expressed as follows [11]: 


$$
\left[\begin{array}{c}
\dot{V}_{y} \\
\ddot{\varphi}
\end{array}\right]=\left[\begin{array}{cc}
-\frac{C_{f}+C_{r}}{m V_{x}} & -V_{x}+\frac{C_{r} l_{r}-C_{f} l_{f}}{m V_{x}} \\
-\frac{l_{f} C_{f}-l_{r} C_{r}}{I_{z} V_{x}} & -\frac{l_{f}^{2} C_{f}+l_{r}^{2} C_{r}}{I_{z} V_{x}}
\end{array}\right]\left[\begin{array}{c}
V_{y} \\
\dot{\varphi}
\end{array}\right]+\left[\begin{array}{c}
\frac{C_{f}}{m} \\
\frac{l_{f} C_{f}}{I_{z}}
\end{array}\right] \delta_{f}
$$

where $V_{x}, V_{y}$ and $\dot{\varphi}$ are the longitudinal velocity, lateral velocity and yaw rate, respectively. $\delta_{f}$ is the steer angle; other parameters are given in Table 1 in Section 3.

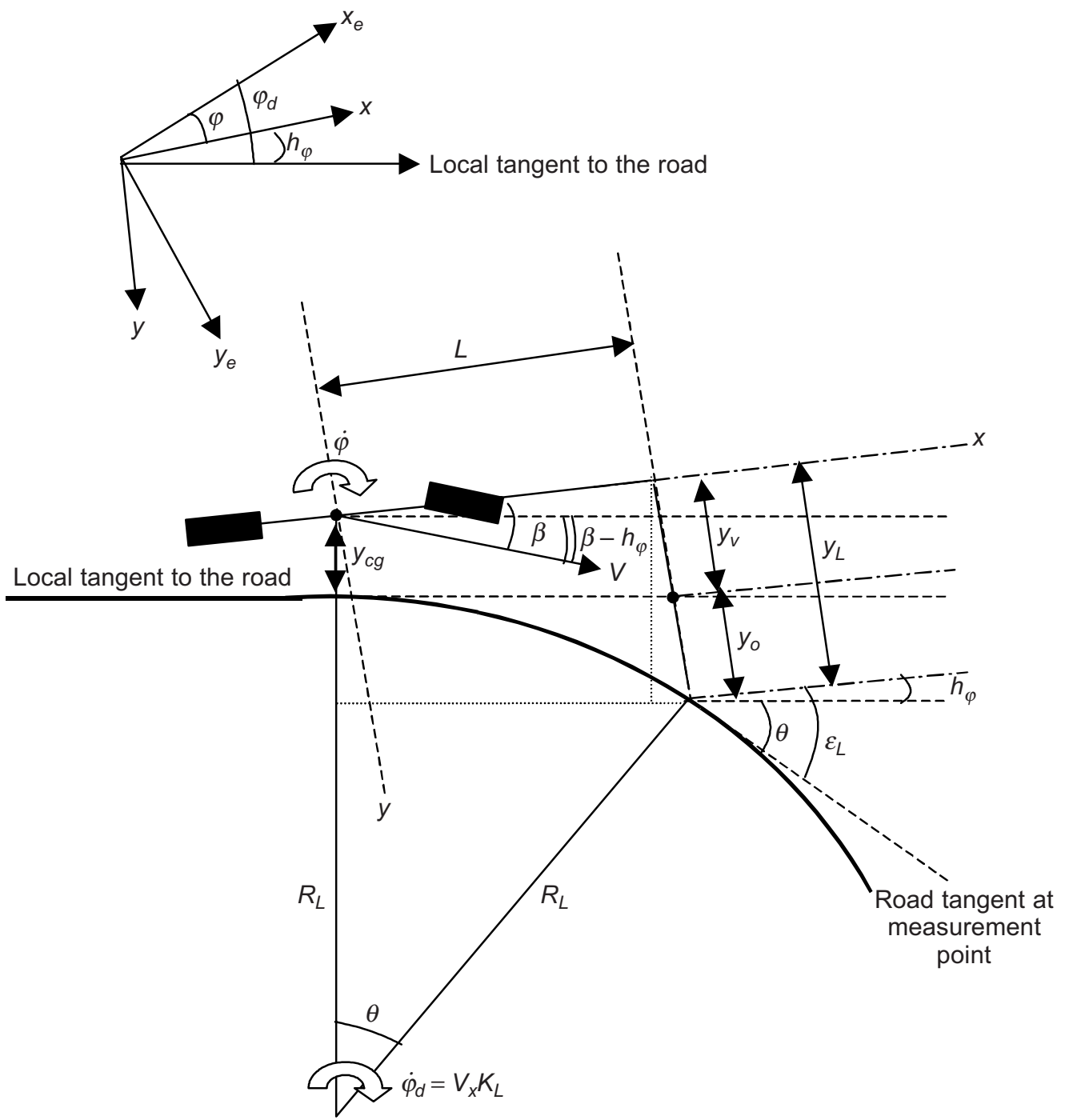

Figure 1 Schematic diagram of road and vehicle model 


\subsection{Vision Dynamics}

The model described by Equation (1) is independent of the road reference. To describe the vehicle relative to the road, the vision dynamics of the system is modeled using visual information and road geometry. Figure 1 shows a vehicle tracking a desired path with road curvature $K_{L}$, where $K_{L}=1 / R_{L} . R_{L}$ is a desired radius of road with instant centre. In this paper, the vehicle is assumed to be equipped with a set of vision system. The vision system is used to estimate the offset from the centerline $y_{L}$ and angle between the road tangent and heading of the vehicle $\varepsilon_{L}$ at some look ahead distance $L$ where measurement is taken. The values of $y_{L}$ and $\varepsilon_{L}$ are used to estimate lateral error $y_{v}$ at some look - ahead distance $L$.

From Figure 1, it can be seen that:

$$
y_{L}=y_{v}+y_{0}
$$

where $y_{L}$ is the actual lateral error at $L$ and $y_{0}$ is the offset because of the road curvature. Refering to Figure 1 and assuming $h_{\varphi}$ is small, the lateral error $y_{v}$ can be expressed as:

$$
y_{v}=y_{c g}+L h_{\varphi}
$$

Also from Figure 1, the rate of $y_{c g}$ is

$$
\dot{y}_{\mathrm{cg}}=V \sin \left(\beta-h_{\varphi}\right) \approx \mathrm{V}\left(\beta-h_{\varphi}\right)=V \beta-V h_{\varphi}
$$

If a set of angles $\beta, \varphi$, and $\delta_{f}$ are also assumed to be small, then the following variables can be defined,

$$
\begin{gathered}
V_{x}=V \cos (\beta)=V \\
V_{y}=V \sin (\beta)=V \beta
\end{gathered}
$$

Substituting Equations (5) and (6) into (4),

$$
\dot{y}_{\mathrm{cg}}=V_{y}-V_{x} h_{\varphi}
$$

Then, the yaw angle $\varphi$ of the vehicle body with respect to the arbitrary reference direction is

$$
\varphi=\varphi_{d}-h_{\varphi}
$$

where $\varphi_{d}$ is the desired yaw angle imposed by the road curvature. The yaw rate relative to the inertial coordinate system is given by:

$$
\dot{\varphi}=\dot{\varphi}_{d}-\dot{h}_{\varphi}
$$

where $\dot{\varphi}_{d}=V K_{L}=V_{x} K_{L}$ is a constant value since road curvature $K_{L}$ and longitudinal velocity $V_{x}$ are assumed to be constant.

Differentiating Equation (3) and substituting Equations (7) and (9) into it, the lateral velocity at the look-ahead distance $L$ is given by: 


$$
\dot{y}_{v}=\dot{y}_{c g}+L \dot{\varphi}=V_{x} h_{\varphi}+L V_{x} K_{L}-L_{\dot{\varphi}}
$$

Then, the vision dynamics which describe the motion of vehicle relative to the road can be represented as:

$$
\begin{gathered}
\dot{y}_{v}=V_{y}-V_{x} h_{\varphi}+L V_{x} K_{L}-L_{\dot{\varphi}} \\
\dot{h}_{\varphi}=V_{x} K_{L}-\dot{\varphi}
\end{gathered}
$$

\subsection{Complete Model}

The complete model consists of the vehicle model of Equation (1) and the vision dynamics of Equations (11) and (12) which can be represented as:

$$
\begin{aligned}
& \dot{x}=A x+B u+E w \\
& y=C_{x}
\end{aligned}
$$

where $x=\left[\begin{array}{llll}V_{y} & \dot{\varphi} & y_{v} & h_{\varphi}\end{array}\right]^{T}, \quad u=\delta_{f}, w=K_{L}$ and $y=\left[\begin{array}{ll}y_{v} & h_{\varphi}\end{array}\right]^{T}$;

$$
\begin{gathered}
A=\left[\begin{array}{cccc}
-\frac{C_{f}+C_{r}}{m V_{x}} & -V_{x}+\frac{C_{r} l_{r}-C_{f} l_{f}}{m V_{x}} & 0 & 0 \\
-\frac{l_{f} C_{f}-l_{r} C_{r}}{I_{Z} V_{x}} & -\frac{l_{f}^{2} C_{f}+l_{r}^{2} C_{r}}{I_{Z} V_{x}} & 0 & 0 \\
1 & -L & 0 & -V_{x} \\
0 & -1 & 0 & 0
\end{array}\right] ; \quad B=\left[\begin{array}{c}
\frac{C_{f}}{m} \\
\frac{l_{f} C_{f}}{I_{Z}} \\
0 \\
0
\end{array}\right] ; \quad E=\left[\begin{array}{c}
0 \\
0 \\
L V_{x} \\
V_{x}
\end{array}\right] \\
C=\left[\begin{array}{cccc}
0 & 0 & 1 & 0 \\
0 & 0 & 0 & 1
\end{array}\right] .
\end{gathered}
$$

The curvature $K_{L}$ enters the model as an exogenous disturbance signal.

\subsection{OPEN LOOP SYSTEM ANALYSIS}

In this paper, we derive the controller based on a single-input single output (SISO) system. This can be done by realizing the complete system of Equation (13) and taking $\delta_{f}$ as the input to the system and $y_{v}$ as the output from the system. From Figure 2, the open-loop transfer function with $K_{L}=0$ is

$$
V(s)=\frac{y_{v}(s)}{\delta_{f}(s)}=\frac{N(s)}{P(s)} ;
$$


where

$$
\begin{aligned}
N(\boldsymbol{s})= & \boldsymbol{s}^{2} V_{x}^{2} C_{f} I_{Z}+\boldsymbol{s} V_{x} C_{r} C_{f}\left(l_{f} l_{r}+l_{r}^{2}\right)+C_{r} C_{f} V_{x}^{2}\left(l_{f}+l_{r}\right) \\
& +L\left(\boldsymbol{s}_{2} V_{x}^{2} C_{f} l_{f} m+\boldsymbol{s} V_{x} C_{r} C_{f}\left(l_{f}+l_{r}\right) ;\right. \\
P(\boldsymbol{s})= & \boldsymbol{s}^{2}\left(\boldsymbol{s}^{2} m V_{x}^{2} I_{Z}+\boldsymbol{s} V_{x}\left(I_{Z}\left(C_{f}+C_{r}\right)+m\left(C_{f} l_{f}^{2}+C_{r} l_{r}^{2}\right)\right)\right. \\
& +m V_{x}\left(C_{r} l_{r}-C_{f} l_{f}\right)+C_{f} C_{r}\left(l_{f}+l_{r}\right)^{2} .
\end{aligned}
$$

The open-loop transfer function with $\delta_{f}=0$ is

$$
D(s)=\frac{y_{v}(s)}{K_{L}(s)}=-\frac{V_{x}^{2}}{s^{2}}
$$

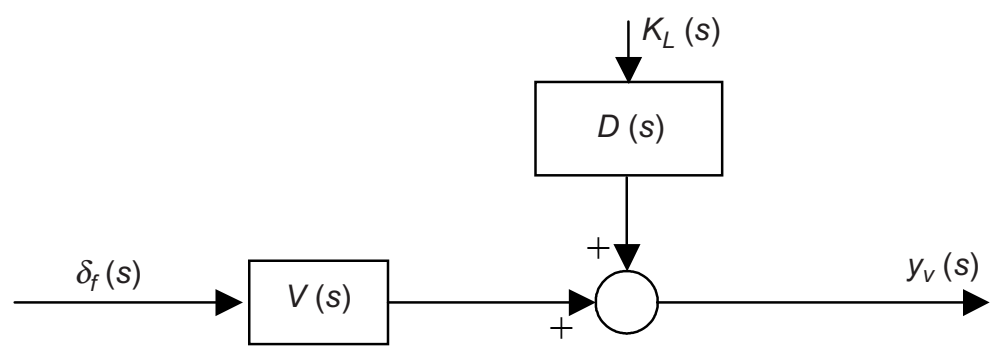

Figure 2 Block diagram for open loop automatic steering control system

The core of the open-loop system analysis lies in understanding the behaviors of the vehicle under various conditions. Notice that the transfer function $V(s)$ from Equation (14) has a pair of poles fixed at the origin, and another two poles and two zeros which characterise the behavior of the vehicle. The poles of $V(s)$ is also a function of longitudinal velocity, $V_{x}$ and the zeros of $V(s)$ is a function of both longitudinal velocity $V_{x}$ and the look-ahead distance $L$. The open-loop analysis of Equation (14) is done using root-locus technique. The parameters for the vehicle are given in Table 1.

Table 1 Parameters of vehicle

\begin{tabular}{ll}
\hline Total mass of the vehicle, $m$ & $1590 \mathrm{~kg}$ \\
Total inertia of vehicle around the CG, $I_{Z}$ & $2920 \mathrm{~kg} \mathrm{~m}{ }^{2}$ \\
Distance of the front axle from the CG, $l_{f}$ & $1.22 \mathrm{~m}$ \\
Distance of the rear axle from the CG, $l_{r}$ & $1.62 \mathrm{~m}$ \\
Cornering stiffness of the front tires, $C_{f}$ & $2 \times 60000 \mathrm{~N} / \mathrm{rad}$ \\
Cornering stiffness of the rear tires, $C_{r}$ & $2 \times 60000 \mathrm{~N} / \mathrm{rad}$ \\
\hline
\end{tabular}


The root loci of the transfer function $V(s)$ with various vehicle parameters are presented in Figures 3 to 6 . From Figure 3, notice that as the longitudinal velocity $V_{x}$ increases from 5 to $30 \mathrm{~m} / \mathrm{s}$, the poles and zeros of the system move towards the right half plane. As a conclusion, the damping ratio, $\zeta$ of the system is decreasing as the longitudinal velocity $V_{x}$ is increasing. The system becomes less stable and exhibit significant oscillatory behavior for higher longitudinal velocity $V_{x}$. Additionally, the response of the system become slower as the longitudinal velocity $V_{x}$ is increasing.

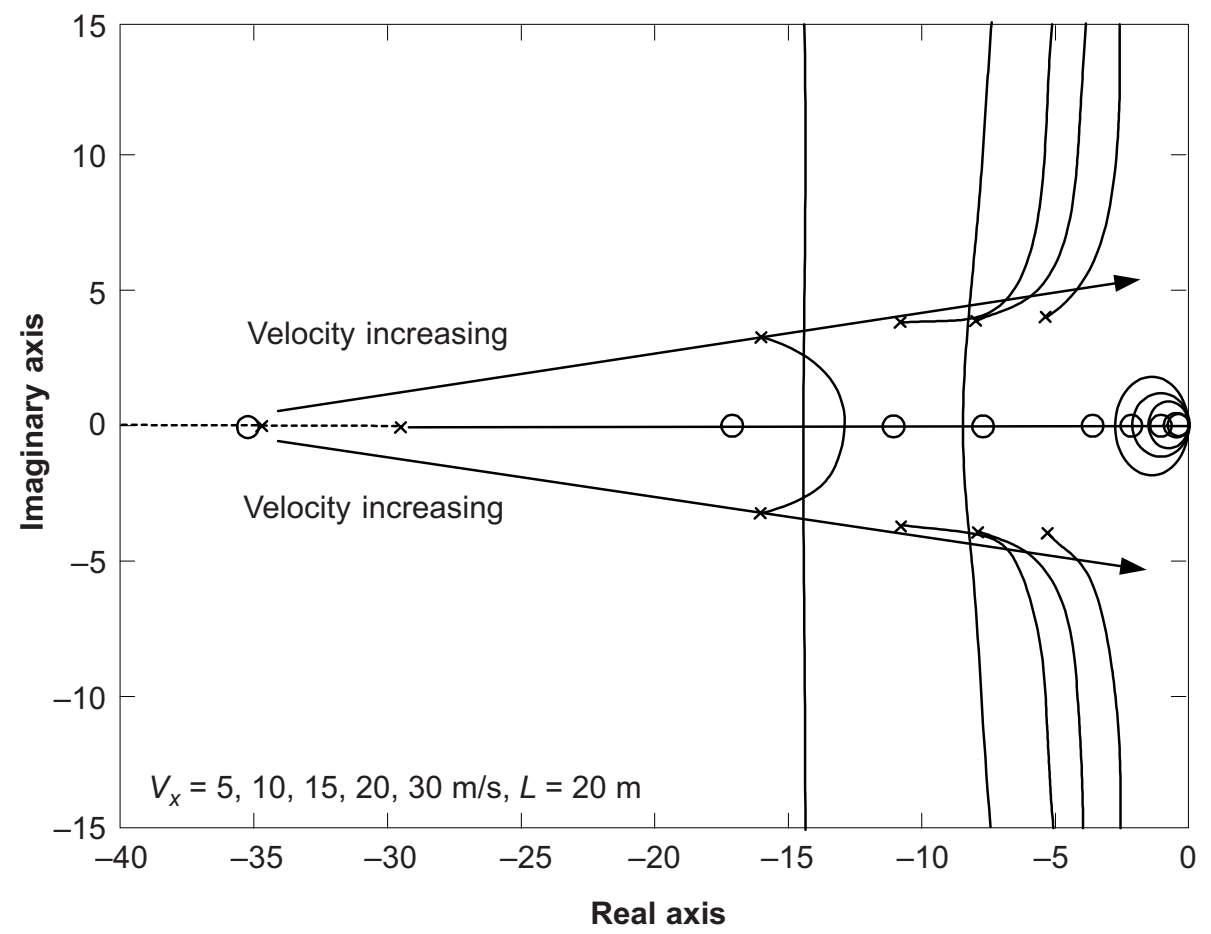

Figure 3 Root locus for $V(s)$ with $V_{x}=5,10,15,20$, and $30 \mathrm{~m} / \mathrm{s}$ with $L=20 \mathrm{~m}$

From Figure 4, notice that as the look-ahead distance $L$ increases, the zeros of the transfer function $V(s)$ move closer to the real axis which will improve the damping of the system. It can be seen that the location of poles is unaffected by the look-ahead distance $L$. As a conclusion, increasing the look-ahead distance $L$ can provide sufficiently good damping to the system by increasing the damping ratio and reducing percentage overshoot. Therefore, the selection of a proper look-ahead distance is important for stability and performance of the system.

Vehicle's load changes as the number of passengers vary. From Figure 5, notice that as the vehicle's load is increasing from 1590 to $2090 \mathrm{~kg}$, the system tends to overshoot and oscillate significantly. 


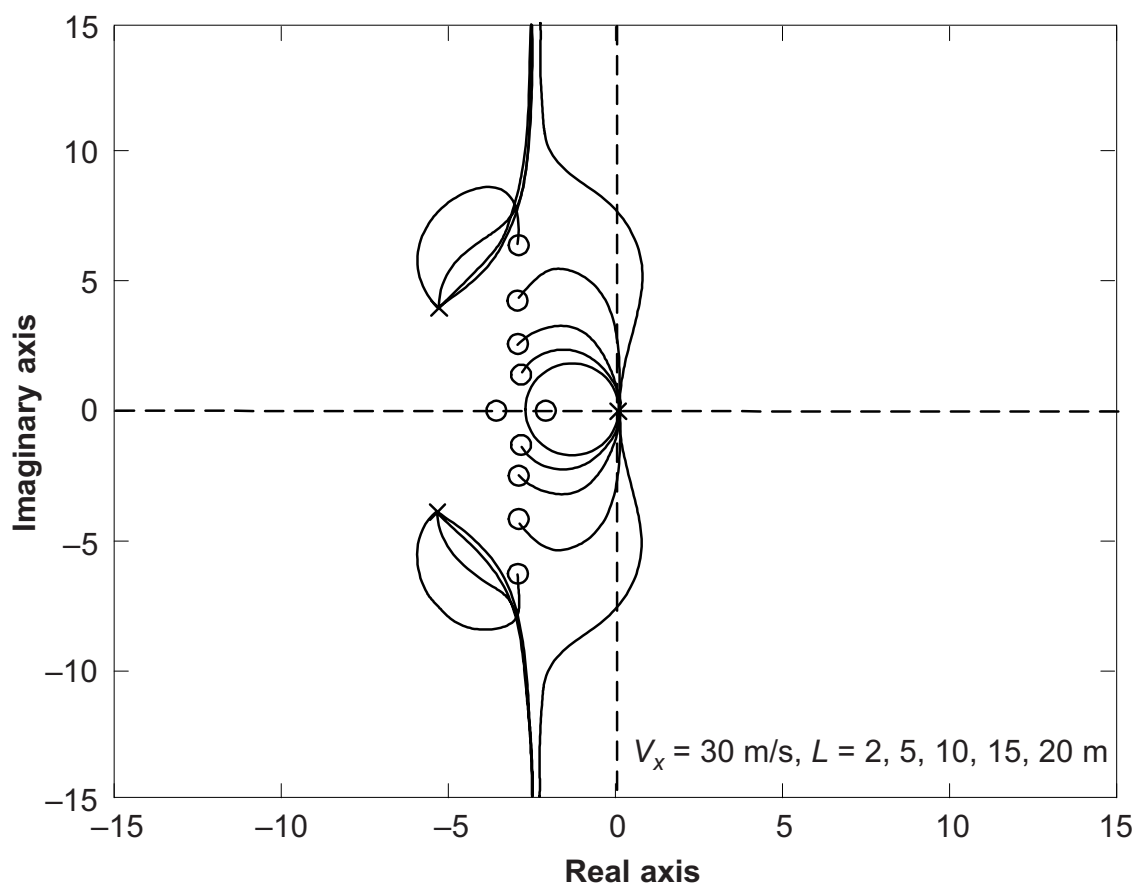

Figure 4 Root locus for $V(s)$ with $L=2,5,10,15,20 \mathrm{~m}$ at $V_{x}=30 \mathrm{~m} / \mathrm{s}$

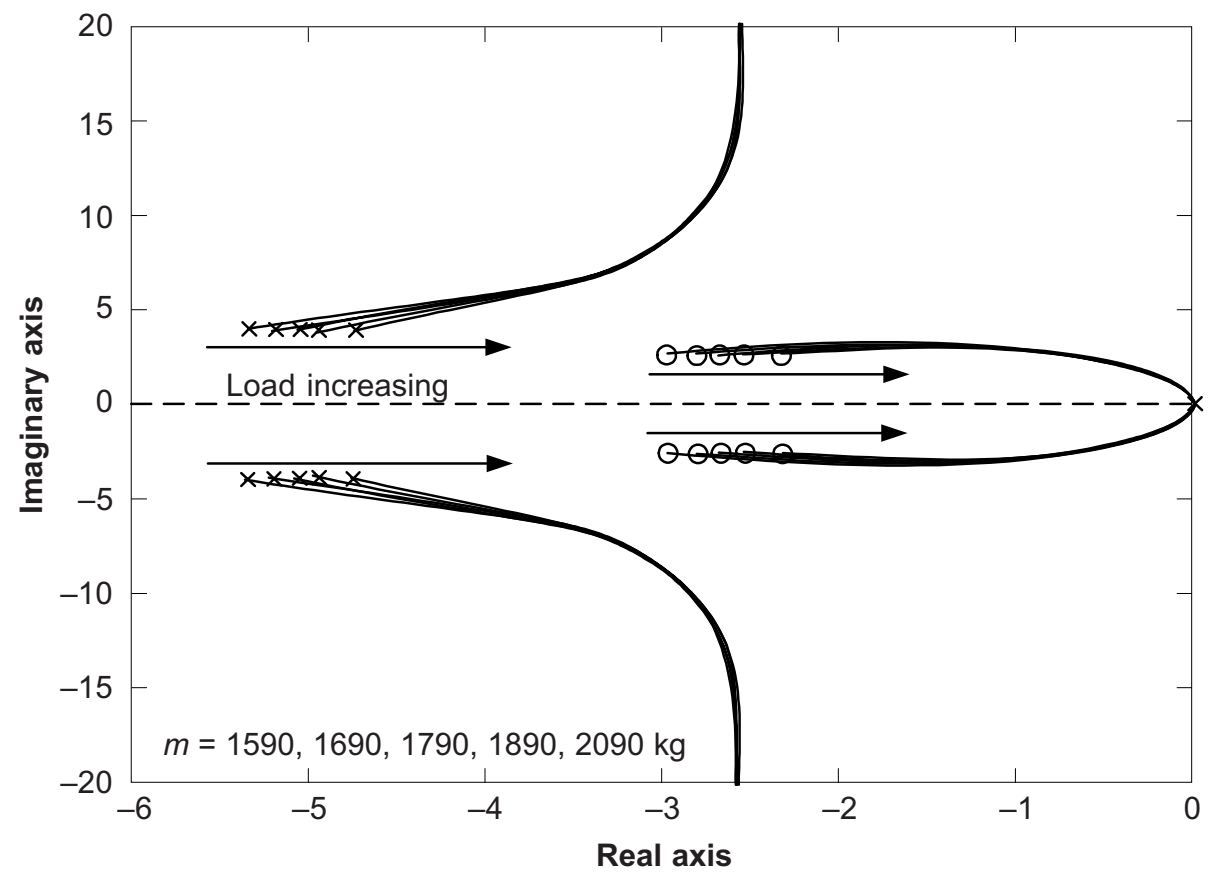

Figure 5 Root locus of $V(s)$ with $L=10 \mathrm{~m}$ at $V_{x}=30 \mathrm{~m} / \mathrm{s}$ under various loads 


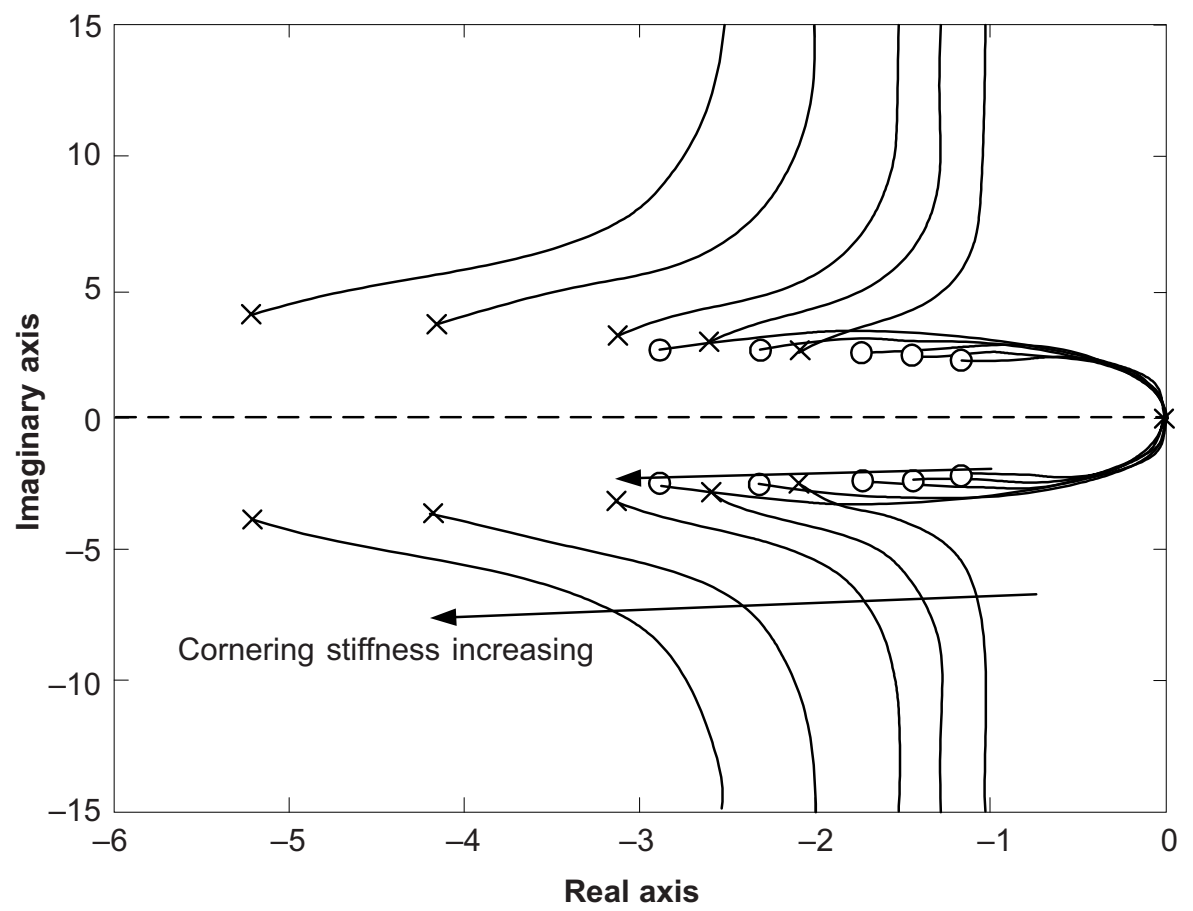

Figure 6 Root locus of $V(s)$ with $L=10 \mathrm{~m}$ at $V_{x}=30 \mathrm{~m} / \mathrm{s}$ under various cornering stiffness

From Figure 6, notice that as the cornering stiffness of the vehicle is decreasing, the damping ratio of the system decreases as well. As a conclusion, the system tends to overshoot and oscillate more significantly at a lower cornering stiffness and higher vehicle load conditions. Therefore, robustness is another important design requirement for an automatic steering control system.

\subsection{CONTROLLER DESIGN}

From the open-loop vehicle model of Equation (13) and disturbance model of Equation (14), the closed-loop system is subjected to one input (steering angle) and another uncontrollable disturbance (road curvature). Subsequently, the automatic steering control problem is to regulate the lateral error $y_{v}$ at some look-ahead distance $L$ equal to zero for any road curvature under various conditions. The selection of a proper look-ahead distance $L$ is crucial for stability and performance of the system and it is made based on root locus analysis as has been shown in the previous section. The output $y_{v}$ of the system can achieve zero steady state error with a step disturbance $A / s^{3}$, where $A=-V_{x}^{2} K_{L}$ by introducing a pure integral into the system. A PID controller is designed by adding one zero and pole as the ideal integral compensator. Meanwhile, another additional zero is added as the ideal derivative 
compensator. Using the root locus technique, controller gains and proper location of the compensator poles and zeros can be specified and fine tuning in order to achieve lower-order approximation by zero-pole cancellation. Figure 7 shows the pole-zero plot for the closed-loop system with a proper tuned PID controller. From Figure 7, notice that three pairs of the pole and zero cancelled each other out. Only one pole on real axis is left alone and dominates the response of the closed-loop system.

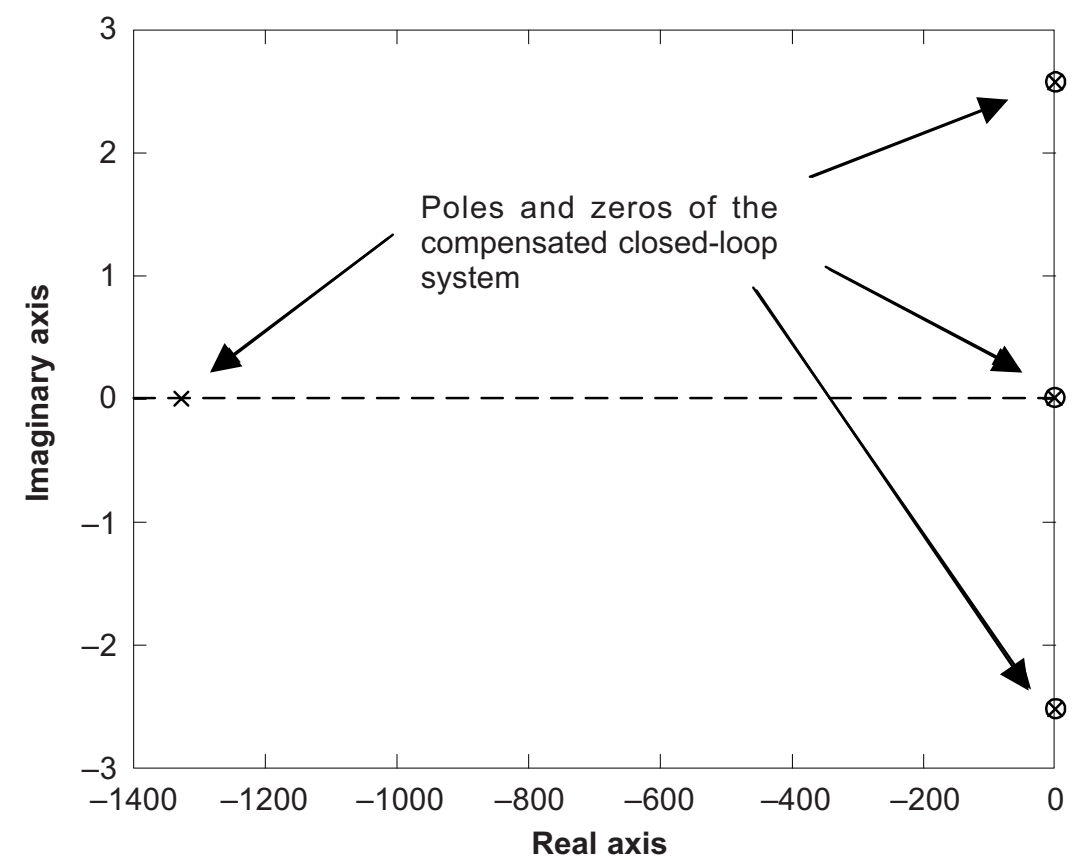

Figure 7 Pole-zero plot for closed-loop system with PID controller

\subsection{SIMULATION}

The new proposed automatic steering control has been tested in simulation using Equations (13) and (14) and the proposed PID controller. Two different analyses were performed: performance and robustness analysis. The simulation block diagram is shown in Figure 8.

The profile of the road curvature used in the simulation is shown in Figure 9. The road profile begins with a straight road segment to analyse the performance of the system to track a straight road. Then, there is a curvature from $K_{L}=0$ to $-0.002 \mathrm{~m}^{-1}$ to analyze the performance of the system to track a curve road under nominal conditions. Following that is a curvature from the left with a maximum 


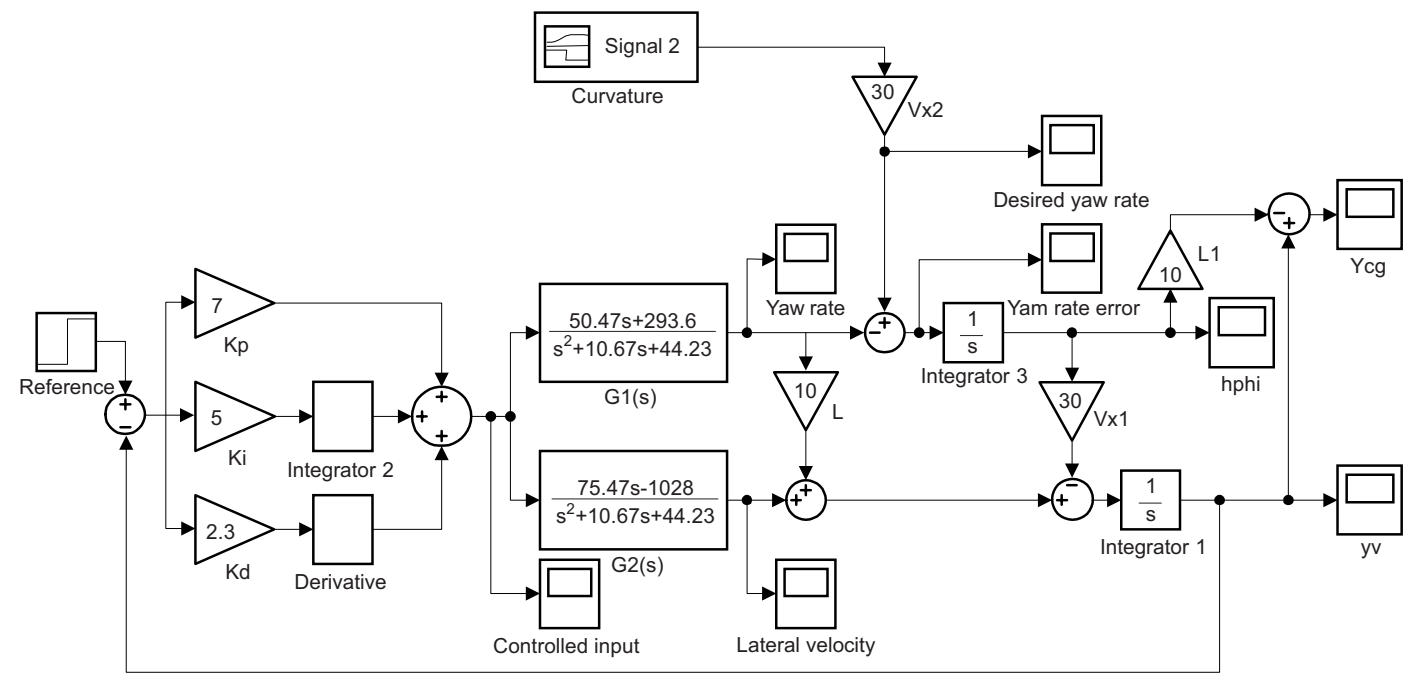

Figure 8 SIMULINK model used in simulation for performance and robustness analysis

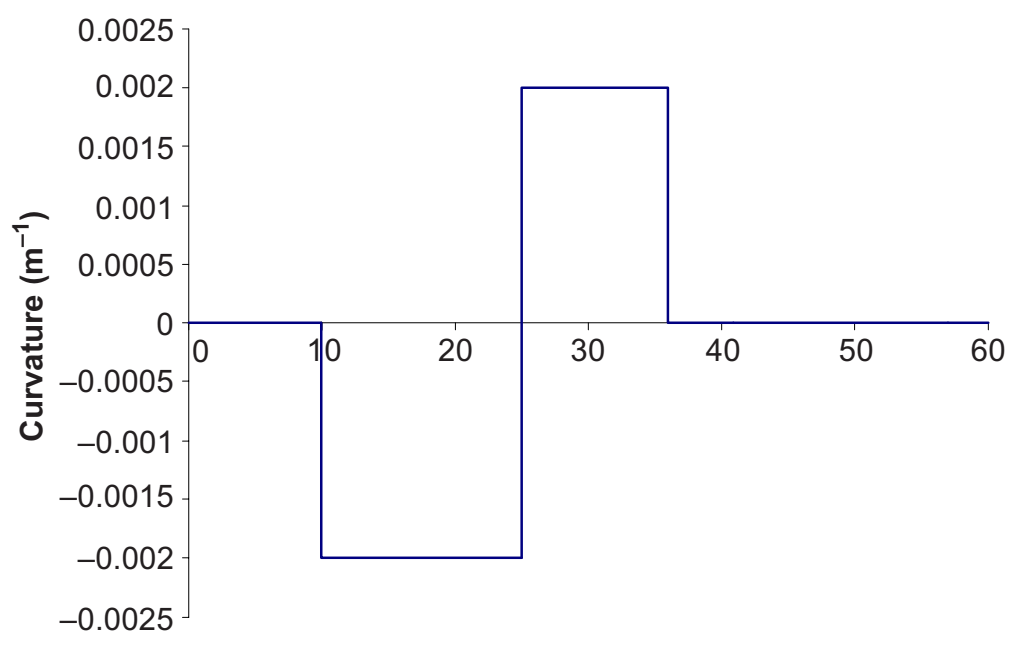

Time (sec)

Figure 9 Profile of the road curvature

curvature of $-0.002 \mathrm{~m}^{-1}$ to the right with a maximum curvature of $0.002 \mathrm{~m}^{-1}$ without intermediate straight segments to analyze the performance of the system to track a curve under extreme condition. Finally, the curvature is reduced to $0 \mathrm{~m}^{-1}$ to analyse the performance of system to track a straight road when exiting from a curve segment. 


\subsection{Performance Analysis}

The performance is analyzed by simulating the closed-loop system with longitudinal velocity $V_{x}=15,20,30 \mathrm{~ms}^{-1}$ and two different values of look-ahead distance $L$ for comparison. From Figures 10 to 14, it is found that the controller is able to compensate the yaw rate error of the system and make the lateral error of the vehicle remains null for various road curvature under various conditions. However, the response of the vehicle tends to overshoot as the longitudinal velocity $V_{x}$ is increased as shown in Figures 10 to 15. Additionally, the system with a smaller look-ahead distance $L$, the lateral error at the center of gravity $y_{c g}$ of the vehicle improved (decreased) significantly as shown in Figures 12 and 15 . However, for a system with high longitudinal velocity $V_{x}$ but small look-ahead distance; the response of the system tends to overshoot extremely. This may caused passengers to be uncomfortable. As a conclusion, the look-ahead distance, $L$ should be adjusted according to the longitudinal velocity, $V_{x}$ of the vehicle in order to get a better performance.

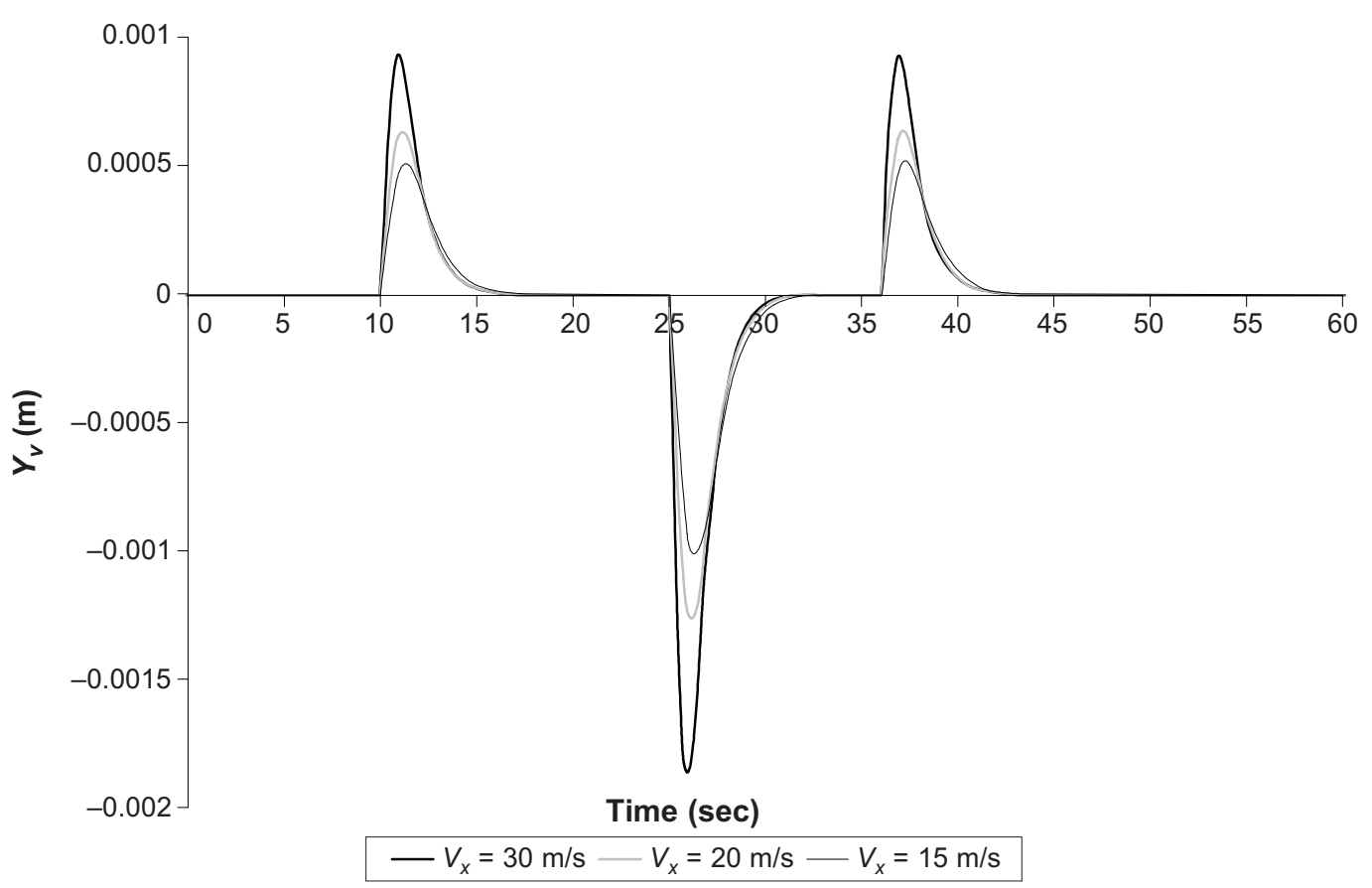

Figure 10 Simulation result of $y_{v}$ with $L=10 \mathrm{~m}$ 


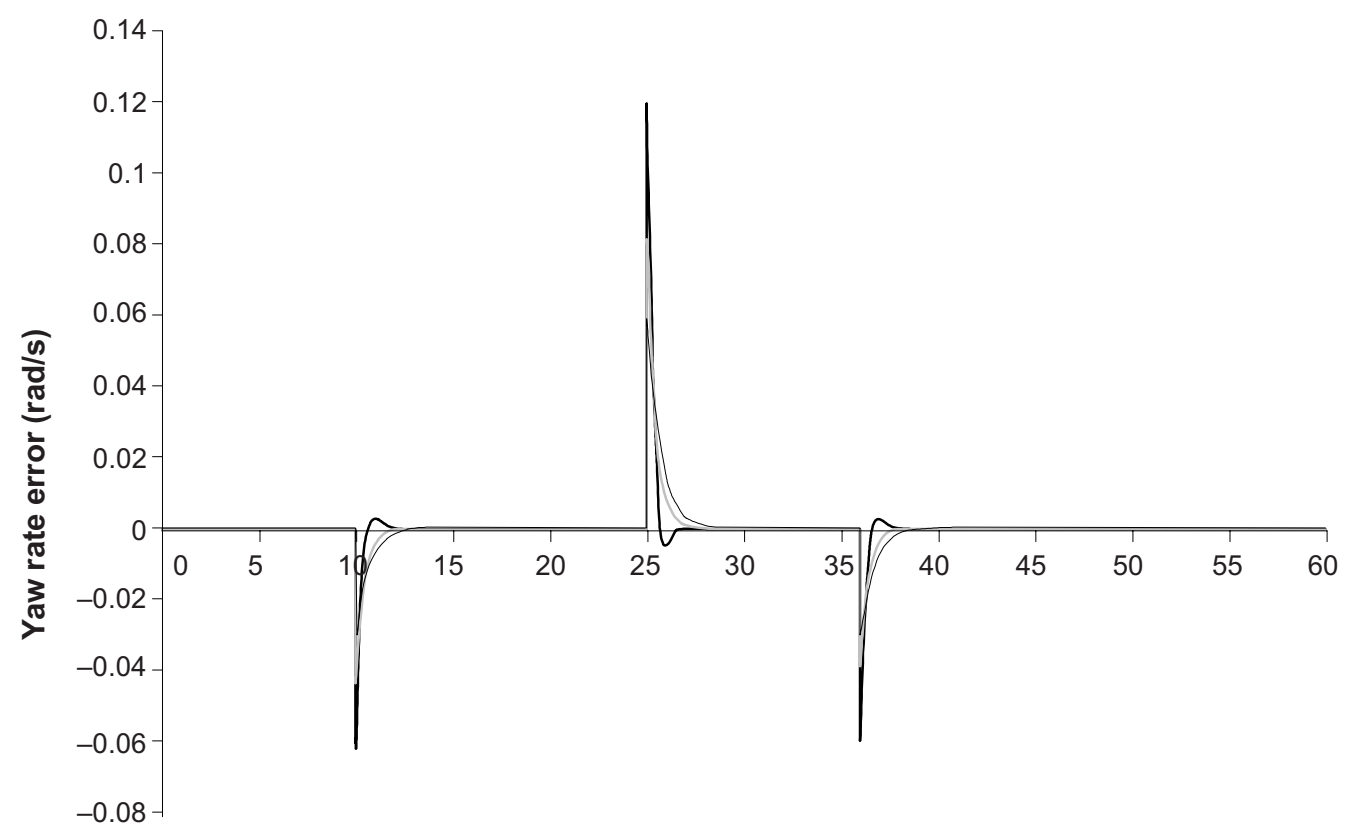

Time (sec)

$-v_{x}=30 \mathrm{~m} / \mathrm{s}-V_{x}=20 \mathrm{~m} / \mathrm{s}-V_{x}=15 \mathrm{~m} / \mathrm{s}$

Figure 11 Simulation result of yaw rate error with $L=10 \mathrm{~m}$

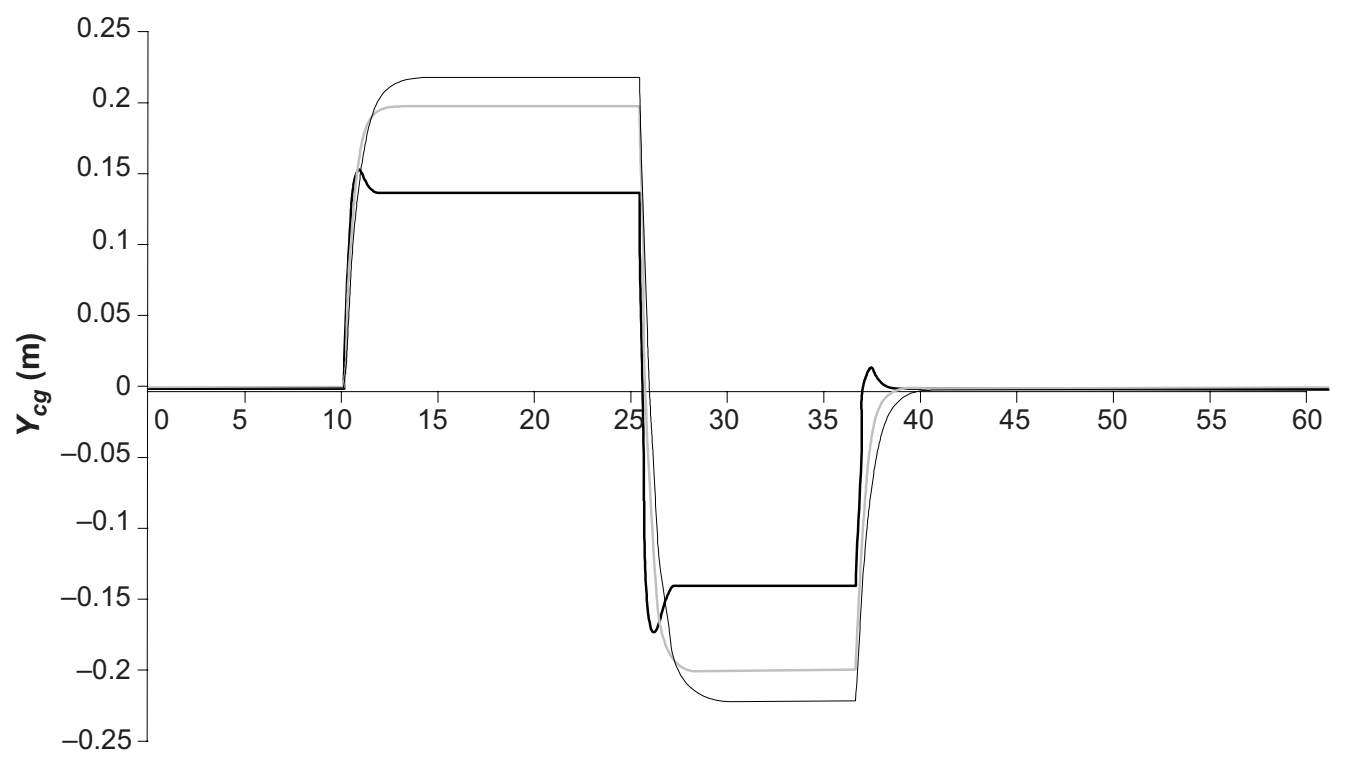

Time (sec)

$-V_{x}=30 \mathrm{~m} / \mathrm{s}-V_{x}=20 \mathrm{~m} / \mathrm{s}-V_{x}=15 \mathrm{~m} / \mathrm{s}$

Figure 12 Simulation result of $y_{c g}$ with $L=10 \mathrm{~m}$ 


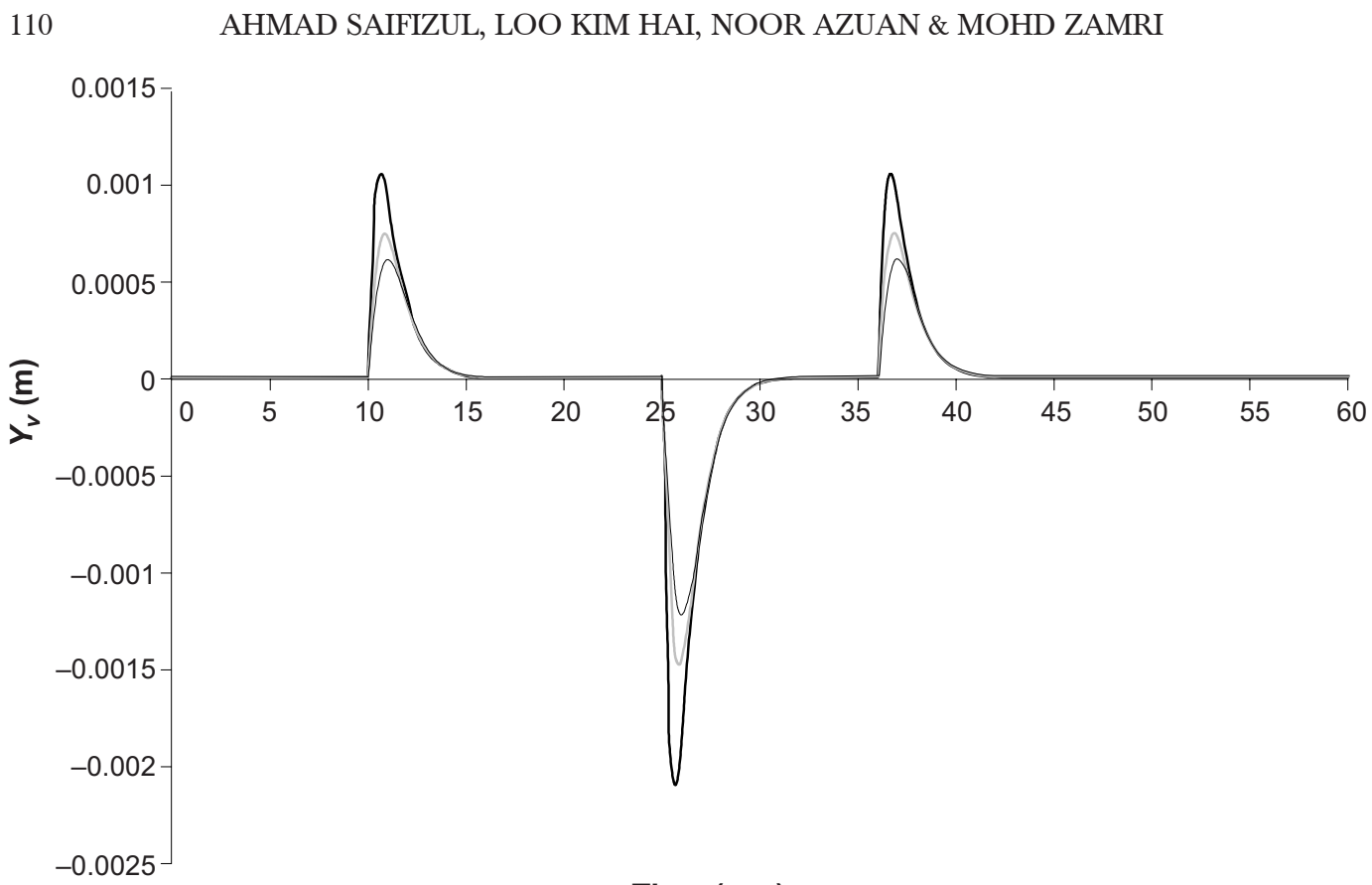

Time (sec)

$-V_{x}=30 \mathrm{~m} / \mathrm{s}-V_{x}=20 \mathrm{~m} / \mathrm{s}-V_{x}=15 \mathrm{~m} / \mathrm{s}$

Figure 13 Simulation result of $y_{v}$ with $L=5 \mathrm{~m}$

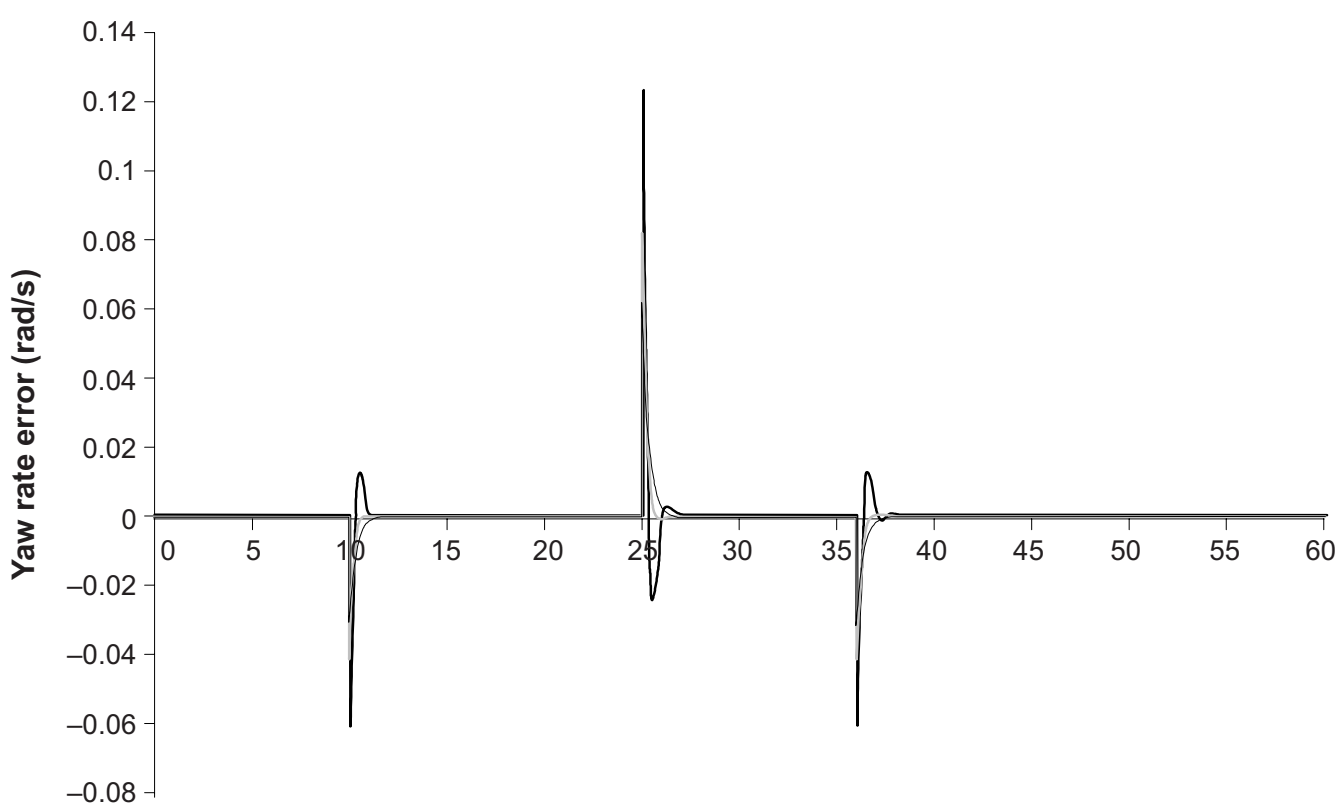

Time (sec)

$-V_{x}=30 \mathrm{~m} / \mathrm{s}-V_{x}=20 \mathrm{~m} / \mathrm{s}-V_{x}=15 \mathrm{~m} / \mathrm{s}$

Figure 14 Simulation result of yaw rate error with $L=5 \mathrm{~m}$ 


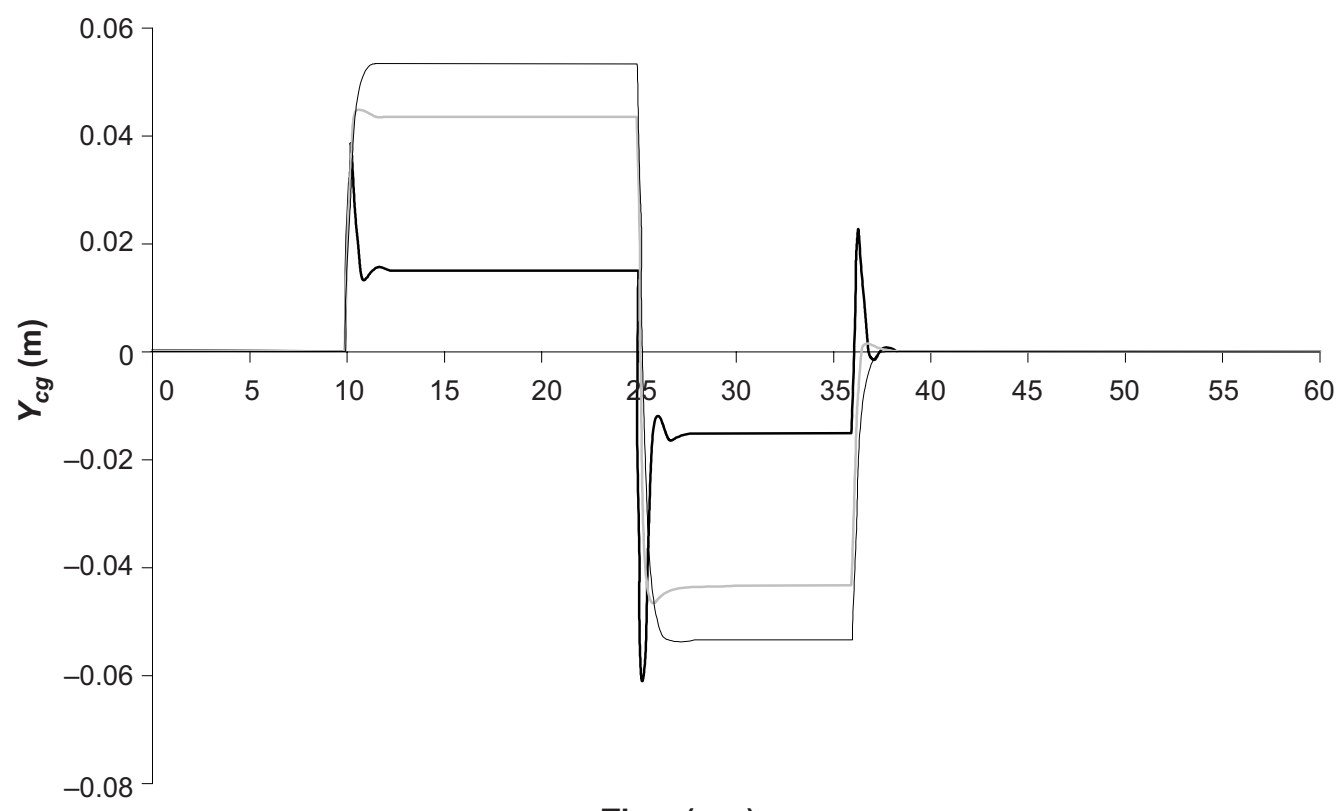

Time (sec)

$-V_{x}=30 \mathrm{~m} / \mathrm{s}-V_{x}=20 \mathrm{~m} / \mathrm{s}-V_{x}=15 \mathrm{~m} / \mathrm{s}$

Figure 15 Simulation result of lateral error at center of gravity $y_{c g}$ with $L=5 \mathrm{~m}$

\subsection{Robustness Analysis}

For robustness analysis of the closed-loop system, comparisons are done by varying the mass and cornering stiffness of the vehicle. First, a robustness analysis is performed to analyse the robustness of the control system under various vehicle load, where the vehicle mass $m=1590,1790$ and $2090 \mathrm{~kg}$. Secondly, another simulation is performed to analyse the robustness of the control system under different road conditions with varying cornering stiffness as $C=C_{r}=C_{f}=120000,96000$ and $60000 \mathrm{~N} / \mathrm{rad}$.

Figures 16 and 17 show that the changes in vehicle's mass (load) and cornering stiffness does effect the performance of the automatic steering control system significantly even though all the errors are still within the acceptable range. 


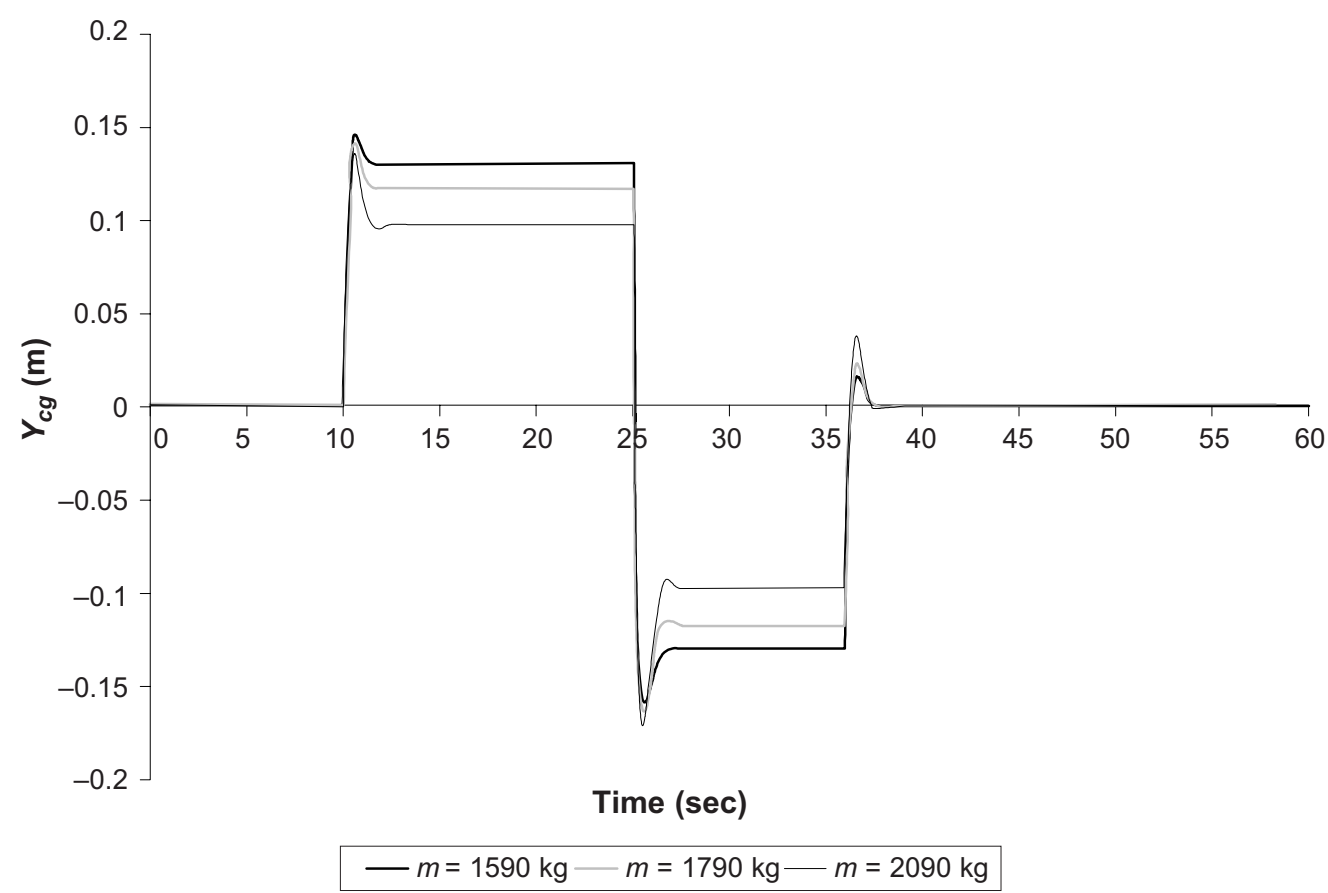

Figure 16 Simulation result for lateral error at center of gravity $y_{c g}$ with $V_{x}=30 \mathrm{~ms}^{-1}$ and $L=10 \mathrm{~m}$ under various vehicle's mass

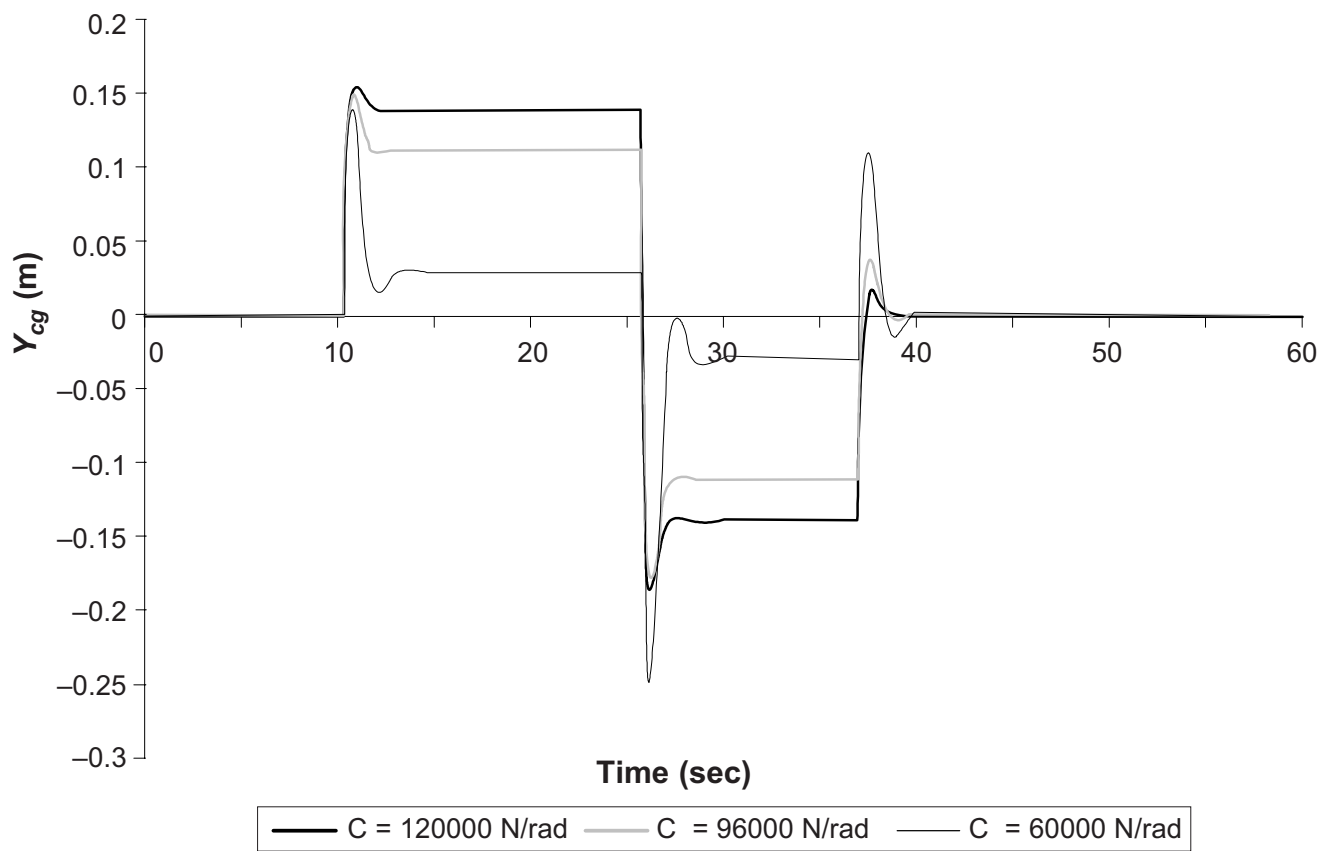

Figure 17 Simulation result for lateral error at center of gravity $y_{c g}$ with $V_{x}=30 \mathrm{~ms}^{-1}$ and $L=10 \mathrm{~m}$ under various road conditions 


\subsection{CONCLUSIONS}

The new proposed automatic steering control based on the look-ahead reference system where the visual information is extracted from image sequences with known camera geometry is employed in the feedback loop of the control system. The proposed PID controller is able to reject the effect of the road curvature disturbance and cause the vehicle to track the reference. However, the vehicle tends to overshoot as the longitudinal velocity of the vehicle is increased. Furthermore, the look-ahead distance, $L$ should also be adjusted according to the longitudinal velocity for a better performance. In general, the primary objective of this research has been achieved where the proposed control system is able to track the centre of a lane automatically with small error under various conditions even though it is less robust.

\section{REFERENCES}

[1] Bender, J. G. 1991. An Overview of System Studies of Automated Highway Systems. IEEE Transactions on Vehicular Technology. 40(1): 82-99.

[2] Shladover, S. E. 1995. Review of the State of Development of Advanced Vehicle Control Systems (AVCS). Vehicle System Dynamics. 24: 551-595.

[3] Segel, L. 1956-57. Theoretical Prediction and Experimental Substantiation of the Responses of the Automobile Steering Control. Proc. Auto. Div. Instn, Mech. Eng. No. 7.

[4] Luong, Q. T., J. Weber, D. Roller, and J. Malik. 1995. An Integrated Stereo-based Approach to Automatic Vehicle Guidance. Proc. of the 5th ICCV. 61-66.

[5] Unyelioglu, A., C. Hatipoglu, and J. Ozguner. 1997. Design and Stability Analysis of a Lane Following Controller. IEEE Transaction on Control Systems Technology. 5(1): 127-134.

[6] Fenton, R. E., G. C. Melocik, and K. W. Olson. 1976. On the Steering of Automated Vehicles: Theory and Experiment. IEEE Transactions on Automatic Control. 21(3): 306-315.

[7] Mayhan, R. J., and R. A. Bishel. 1982. A Two-frequency Radar for Vehicle Automatic Control. IEEE Trans. on Vehicular Technology. 31(1): 450-466.

[8] Zhang, W., and R. E. Parsons. 1990. An Intelligent Roadway Reference System for Vehicle Lateral Guidance/Control. Proc. American Control Conf. San Diego, CA, USA. 281-286.

[9] Shiadover, S. E. 1992. The California PATH Program and its Approach to Vehicle-highway Automation. Proc. Intelligent Vehicles Symp. Detroit. 347-352.

[10] Guldner, J., H. S. Tan, and S. Patwardhan. 1997. On Fundamental Issues of Vehicle Steering Control for Highway Automation. Technical Report UCB-ITS-PWP-97-11. Program on Advanced Technology for the Highway. Institute of Transportation Studies, University of California, Berkeley.

[11] Peng, H., and M. Tomizuka. 1990. Vehicle Lateral Control for Highway Automation. American Control Conference. San Diego, CA. 281.

[12] Hessburg, T., and M. Tomizuka. 1991. A Fuzzy Rule-based Controller for Automotive Vehicle Guidance. Technical Report UCB-ITS-PRR-91-18. Program on Advanced Technology for the Highway. Institute of Transportation Studies, University of California, Berkeley.

[13] Peng, H., and M. Tomizuka. 1993. Preview Control for Vehicle Lateral Guidance in Highway Automation. ASME Journal of Dynamic Systems, Measurement and Control. 115(4): 678-686.

[14] Pham, H., K. Hedrick, and M. Tomizuka. 1994. Combined Lateral and Longitudinal Control of Vehicles. Proceedings of the American Control Conference. Baltimore, Maryland. 1205-1206.

[15] Ackermann, J., J. Guldner, W. Sienel, and R. Steinhauser. 1995. Linear and Nonlinear Controller Design for Robust Automatic Steering. IEEE Trans. on Control Systems Technology. 3: 132-143.

[16] Chen, C., and M. Tomizuka. 1997. Vehicle Lateral Control on Automated Highways: A Backstepping Approach. Proceedings of the IEEE Conference on Decision and Control. San Diego, CA, USA. 
[17] Saifizul, A. A., and S. Hosoe. 2003. Passivity Based Control of Automated Driver Based on Velocity Field. Proceedings of 2nd IFAC Conference Control Systems Design. Bratislava, Slovak Republic. CDROM.

[18] Hessburg, T., M. Tomizuka., H. Peng, and W. B. Zhang. 1991. An Experimental Study on Lateral Control of a Vehicle. Technical Report. UCB-ITS-PRR-91-17. Program on Advanced Technology for the Highway. Institute of Transportation Studies, University of California, Berkeley.

[19] Kosecka, J. 1997. Vision Based Lateral Control of Vehicle: Look - Ahead and Delay Issues. Internal memo. Department of EECS, University of California, Berkeley.

[20] Lugner, P. 1997. The Influence of the Structure of Automobile Models and Type Characteristics on the Theoretical Results of Steady-State and Transient Vehicle Performance. The Dynamics of Vehicles. Proceedings of 5th VSD-and IUAM Symposium. Vienna, Austria.

[21] Peng, H., and M. Tomizuka. 1990. Lateral Control of Front-Wheel Steering Rubber-Tire Vehicles. California PATH Report, UCB-ITS-PRP-90-5. 